\title{
Pharmacokinetics of Hydroxyprogesterone Caproate and its Primary Metabolites during Pregnancy
}

\author{
Kim A. Boggess, $M D^{1}$ Jeffrey B. Baker, $\mathrm{MD}^{2}$ Amy P. Murtha, $\mathrm{MD}^{3}$ Alan M. Peaceman, $\mathrm{MD}^{4}$ \\ Dinesh M. Shah, MD ${ }^{5}$ Sylvia L. Siegfried, $\mathrm{MD}^{6} \quad$ Robert Birch, $\mathrm{PhD}^{7}$
}

\author{
${ }^{1}$ University of North Carolina at Chapel Hill, Chapel Hill, North Carolina \\ 2 Rosemark Women Care Specialists, Idaho Falls, Idaho \\ ${ }^{3}$ Duke University, Durham, North Carolina \\ ${ }^{4}$ Northwestern University, Chicago, Illinois \\ ${ }^{5}$ University of Wisconsin, Madison, Wisconsin \\ ${ }^{6}$ Altus Research Inc., Lake Worth, Florida \\ ${ }^{7}$ AMAG Pharmaceuticals, Waltham, Massachusetts
}

Address for correspondence Kim A. Boggess, MD, Department of OB/ GYN, University of North Carolina at Chapel Hill, 3010 Old Clinical Building, CB \#7570, Chapel Hill, NC 27599-7570 (e-mail: kboggess@med.unc.edu).

Am J Perinatol Rep 2018;8:e106-e112.

\begin{abstract}
Keywords

- gestation

- hydroxyprogesterone

- metabolites

- pharmacokinetics

- pregnancy

- preterm birth

Objective To measure pharmacokinetics of hydroxyprogesterone caproate (OHPC) and its major metabolites throughout pregnancy.

Study Design Thirty women were prescribed OHPC for recurrent preterm birth prevention. Three cohorts of subjects had blood drawn for 7 consecutive days at one of three times: cohort $1(n=6)$ after the first dose (weeks 16-20), cohort $2(n=8)$ between weeks 24 and 28 , and cohort $3(n=16)$ between weeks 32 and 36. We measured serum trough levels after week 1 in cohort 1 or after two consecutive weekly doses in cohorts 2 and $3 . \ln 10$ subjects, we estimated OHPC terminal half-life at 28 days after their last dose.

Results In cohorts 1,2 , and 3 , the areas under curve $(\mathrm{ng} \times \mathrm{h} / \mathrm{mL}$ ) for OHPC were $571.4 \pm 195.2,1,269.6 \pm 285.0$, and 1,268.0 \pm 511.6, respectively. Maximum OHPC levels $(\mathrm{ng} / \mathrm{mL})$ were $5.0 \pm 1.5,12.5 \pm 3.9$, and $12.3 \pm 4.9$, respectively. The areas under the curve for mono-hydroxylated metabolites were $208.5 \pm 92.4,157.1 \pm 64.6$, and $211.2 \pm 113.1$, and maximum concentrations were $1.9 \pm 0.7,1.5 \pm 0.7$, and $1.8 \pm 1.0$, respectively. Di-hydroxylated metabolite levels were significantly lower than mono-hydroxylated metabolites. Estimated terminal half-life of OHPC was $16.3 \pm 3.6$ days and $19.7 \pm 6.2$ days for the mono-hydroxylated metabolites.

Conclusion After the first injection, OHPC maximum serum level was approximately half steady-state level. Measurable metabolites of unknown activity were detected.
\end{abstract}

Worldwide, preterm birth (PTB), delivery prior to 37 weeks of gestation, is the most common cause of neonatal death and the second most common cause of death in children under age 5 years. ${ }^{1}$ According to the U.S. Centers for Disease Control and Prevention, the U.S. incidence of PTB peaked in 2006 at $12.8 \%$. This represented a $21 \%$ increase since 1990 and a $33 \%$ increase from 1981 to $2004 .^{2}$ Since 2006 , the rate has fallen slightly to a rate of $11.4 \%$ in $2013 .^{3}$

received

October 9, 2017

accepted after revision

January 15, 2018
DOI https://doi.org/

10.1055/s-0038-1639331. ISSN 2157-6998.
PTB may occur spontaneously or owing to a medical indication. One significant risk factor for spontaneous PTB is previous pregnancy history. Women with a prior spontaneous PTB have a 2.5-fold greater risk for subsequent spontaneous PTB than those without. In 2011, the U.S. Food and Drug Administration (FDA) approved hydroxyprogesterone caproate (17-OHPC) injection to reduce the risk of recurrent spontaneous PTB in women with a singleton pregnancy and

Copyright $\odot 2018$ by Thieme Medical Publishers, Inc., 333 Seventh Avenue, New York, NY 10001, USA. Tel: +1(212) 584-4662.
License terms

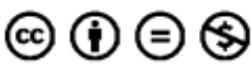


history of prior singleton spontaneous PTB. At the time of the FDA approval, limited data were available on the pharmacokinetics (PK) of 17-OHPC in pregnant women, and no human PK studies quantitating 17-OHPC metabolites exist. Our objective was to measure the PK of 17-OHPC and its major metabolites throughout pregnancy.

\section{Materials and Methods}

\section{Study Design}

From July 1, 2013 to November 16, 2014, we conducted protocol HPC-PK-005 at six U.S. academic and community centers. Each study site had institutional review board approval, and all women gave written informed consent to participate. Thirty-one eligible women prescribed 17-OHPC (Makena ${ }^{\circledR}$, Hospira Inc., McPherson, KS) for recurrent PTB prevention were approached, and 30 agreed to participate. Subjects had blood drawn for 7 consecutive days at one of three times throughout the pregnancy: cohort $1(n=6)$ after the first dose (weeks $16-20)$, cohort $2(n=8)$ between weeks 24 and 28 , and cohort $3(n=16)$ between weeks 32 and 36 (-Table 1). We measured serum trough level after week 1 in cohort 1 or after 2 consecutive weekly doses in cohorts 2 and 3 . In 10 subjects, we estimated 17-OHPC terminal half-life at 28 days after their last dose.

After enrollment, medical and obstetric history was obtained, at least one prior PTB was documented, and subjects underwent a brief physical examination. Maternal race/ethnicity was self-reported. Gestational age was based upon the date of the last menstrual period unless the subject was unsure of the date, or it was inconsistent with ultrasound when ultrasound assessment was used. A 1-mL intramuscular injection containing 17-OHPC $250 \mathrm{mg}$ was administered into the upper outer quadrant of the gluteus maximus. At weekly visits, we documented adverse events, maternal complications, and pregnancy complications. Subjects were followed up until delivery, and infants were followed until the later of 28 days of life or discharge from the neonatal intensive care unit (NICU).

\section{Blood Sample Analysis}

Maternal blood was collected into $10-\mathrm{mL}$ lavender-top vacutainers containing ethylenediaminetetraacetic acid. Samples were gently inverted 5 to 10 times and centrifuged at 1,100 to $1,800 \times g$ for 10 to 15 minutes. Plasma was transferred equally into two 5-mL cryovials and frozen at $-20^{\circ} \mathrm{C}$ or below.

Covance Inc. (West Trenton, NJ) measured 17-OHPC using a validated bioanalytical method. 17-OHPC (US Pharmacopeia) was used as a reference material and 4-Pregnen-17 $\alpha$ ol-3,20-dione-2,2,4,6,6,21,21,21-d8 Hexanoate as an internal standard. Analysis was performed in staggered parallel mode using an ARIA-TX4 HPLC system with API4000 MS detection. Plasma samples were analyzed in accordance with the laboratory's standard operating procedures. A single analysis was performed on each sample. Each run included a duplicate calibration curve, a matrix blank, a control zero sample (matrix blank containing internal standard), and duplicate undiluted quality control (QC) samples at four concentrations within the calibration range. The calibration standards were placed at the beginning and end of each analytical run, and the QC samples were interspersed with study samples within each analytical run. Dilution QC samples were included in any run where samples were diluted prior to analysis.

There is no commercially available assay for 17-OHPC metabolites, thus Research Triangle Institute (Research Triangle Park, NC) developed a metabolite assay using synthesized standards, with purity by high performance liquid chromatography of $99.3 \%$. For standards, $0.5 \mathrm{~mL}$ of blank human plasma was mixed with $0.5 \mathrm{~mL}$ of $2 \%$ formic acid and $25 \mu \mathrm{L}$ of internal standard (MPA $1 \mu \mathrm{g} / \mathrm{mL}$ ) and $5 \mu \mathrm{L}$ of standard spike. The samples were vortexed and extracted on an Oasis HLB 3 cc solid phase extraction cartridge preconditioned with methanol $(2 \mathrm{~mL})$ followed by water $(2 \mathrm{~mL})$. Cartridges were washed with $5 \%$ methanol and then eluted with 2-mL methanol under vacuum at $10 \mathrm{~mm} \mathrm{Hg}$. The methanol extracts were dried on a Turbovap LV under nitrogen and were resolubilized in $100 \mu \mathrm{L}$ of 50:50 acetonitrile:water with $0.1 \%$ formic acid by vortexing ( $30 \mathrm{~s}$ ); $20 \mu \mathrm{L}$ of each was injected on an Applied Biosystems API-5000 triple quadrupole mass spectrometer equipped with a Waters Acquity Ultra-Performance Liquid Chromatography. Plasma samples were thawed on ice and were briefly vortexed to ensure homogeneity. An aliquot $(0.5 \mathrm{~mL})$ was removed from each plasma sample, mixed with methanol $(5 \mu \mathrm{L})$ and $2 \%$ formic acid in water $(0.5 \mathrm{~mL})$, and extracted as above.

Mono-hydroxylated hydroxyprogesterone caproate (17$\mathrm{OHPC}-\mathrm{OH})$ levels were determined $(\mathrm{ng} / \mathrm{mL})$ based on standard curves. As no di-hydroxylated hydroxyprogesterone

Table 1 Study cohort blood-draw schedule for pharmacokinetic measurements

\begin{tabular}{|l|l|l|l|}
\hline Cohort & Following first dose & Weeks $24-28$ & Weeks 32-36 \\
\hline $1(n=6)$ & Daily for 7 days to establish $C_{\max }$ & Two consecutive trough levels & Two consecutive trough levels \\
\hline $2(n=8)$ & Prior to dose 2 & Daily for 7 days to establish $C_{\max }$ & Two consecutive trough levels \\
\hline $3(n=16)$ & Prior to dose 2 & Two consecutive trough levels & Daily for 7 days to establish $C_{\text {max }}$ \\
\hline Elimination phase & $\begin{array}{l}\text { Blood levels collected for } 5 \text { of the } 7 \text { days following the final dose, omitting the weekends and within } \pm 1 \text { day } \\
\text { of days } 11,17,24, \text { and } 28 .\end{array}$ \\
\hline
\end{tabular}

Abbreviation: $C_{\max }$, maximum concentration. 
caproate (17-OHPC-diOH) standard is available, we estimated levels using the 17-OHPC-OH standard curve. Limits of quantification for the standards were $0.5 \mathrm{ng} / \mathrm{mL}$ for 17-OHPC and $0.1 \mathrm{ng} / \mathrm{mL}$ for $17-\mathrm{OHPC}-\mathrm{OH}$, and the inter assay precision ranged from 2.5 to $6.8 \%$.

\section{PK Analysis}

Subjects were included in PK assessments if multiple blood draws following a dose of 17-OHPC were scheduled and at least one blood draw obtained. Subjects were included in trough-level assessments in each interval if they did not have a PK assessment and had blood drawn immediately prior to at least one dose of 17-OHPC. 17-OHPC and metabolites plasma PK measurements included area under the plasma concentration-time curve (AUC) from time $=1$ to the last measurable concentration $\left(A U C_{\text {last }}\right)$, maximum observed concentration $\left(C_{\max }\right)$, time at which maximum concentration is observed $\left(T_{\max }\right)$, terminal elimination half-life $\left(T_{1 / 2}\right)$, and trough concentrations $\left(C_{\text {trough }}\right)$.

17-OHPC PK measurements were calculated using SAS ${ }^{\circledR}$ for Windows Version 9.4. PK mono- and di-hydroxylated metabolite measurements were calculated using a noncompartmental analysis in Phoenix WinNonlin Version 6.3. For PK analysis, plasma levels below limit of detection at predose to the first concentration imputed to 0 , and those that occur thereafter were treated as missing.

\section{Statistical Methods}

Data were collected using an electronic data capture system (Cmed, Timaeus Inc., Horsham, United Kingdom) and a contract research organization (ResearchPoint Global Austin, TX) monitored study records for data completeness and quality. We calculated mean, median, standard deviation (SD), and range for continuous variables, and frequency and percentage for categorical variables.

\section{Results}

\section{Study Population}

- Table 2 shows subject characteristics. Two-thirds were Caucasian, 10\% reported smoking during pregnancy, and mean \pm SD pre-pregnancy body mass index (BMI) was $31.9 \pm 10.3 \mathrm{~kg} / \mathrm{m}^{2}$. The median number of prior preterm deliveries was one, and 11 (37\%) subjects had more than one prior PTB.

Twenty (67\%) of 30 subjects received 17-OHPC through gestational week 36 . Six subjects discontinued early due to a premature delivery, one declined the week-36 dose, one was incarcerated and thus withdrawn at the time of incarceration, one was found to be ineligible and was withdrawn after one dose, and one did not receive the week-36 dose due to scheduling difficulties. All subjects in cohorts 1 and 2 had blood drawn for PK measurements, as did 11 of 16 subjects in

Table 2 Study cohort characteristics and previous pregnancy history

\begin{tabular}{|c|c|c|c|c|}
\hline & $\begin{array}{l}\text { All subjects } \\
(N=30)\end{array}$ & $\begin{array}{l}\text { Cohort } 1 \\
(n=6)\end{array}$ & $\begin{array}{l}\text { Cohort } 2 \\
(n=8)\end{array}$ & $\begin{array}{l}\text { Cohort } 3 \\
(n=16)\end{array}$ \\
\hline \multicolumn{5}{|l|}{ Age (years) } \\
\hline Mean \pm SD & $29.4 \pm 5.5$ & $29.4 \pm 6.6$ & $29.4 \pm 6.6$ & $29.4 \pm 6.6$ \\
\hline \multicolumn{5}{|l|}{ Ethnicity, $n$ (\%) } \\
\hline Hispanic or Latino & $2(6.7)$ & $0(0.0)$ & $1(12.5)$ & $1(6.3)$ \\
\hline Non-Hispanic or non-Latino & $28(93.3)$ & $6(100.0)$ & $7(87.5)$ & $15(93.8)$ \\
\hline \multicolumn{5}{|l|}{ Race, $n(\%)$} \\
\hline White & $20(66.7)$ & $4(66.7)$ & $6(75.0)$ & $10(62.5)$ \\
\hline $\begin{array}{l}\text { Black, African-American, } \\
\text { or African heritage }\end{array}$ & $10(33.3)$ & $2(33.3)$ & $2(25.0)$ & $6(37.5)$ \\
\hline \multicolumn{5}{|l|}{ Pre-pregnancy weight (kg) } \\
\hline Mean \pm SD & $83.8 \pm 27.58$ & $67.5 \pm 15.6$ & $87.2 \pm 33.5$ & $88.2 \pm 27.1$ \\
\hline \multicolumn{5}{|l|}{ Pre-pregnancy BMI $\left(\mathrm{kg} / \mathrm{m}^{2}\right)$} \\
\hline Mean \pm SD & $31.9 \pm 10.3$ & $27.0 \pm 7.0$ & $33.1 \pm 12.1$ & $33.1 \pm 10.4$ \\
\hline \multicolumn{5}{|l|}{ Substance abuse, $n(\%)$} \\
\hline Smoking & $3(10.0)$ & $1(16.7)$ & 0 & $2(12.5)$ \\
\hline Alcohol & 0 & 0 & 0 & 0 \\
\hline Drugs & $2(6.7)$ & $1(16.7)$ & 0 & $1(6.3)$ \\
\hline \multicolumn{5}{|l|}{ Previous preterm births } \\
\hline Mean \pm SD & $1.6 \pm 1.1$ & $2.2 \pm 2.0$ & $1.8 \pm 0.7$ & $1.3 \pm 0.6$ \\
\hline$>1$ Previous preterm birth, $n(\%)$ & $11(36.7)$ & $2(33.3)$ & $5(62.5)$ & $4(25.0)$ \\
\hline
\end{tabular}

Abbreviations: BMI, body mass index; SD, standard deviation.

Data shown as column number (\%) or as continuous values with SD. 
cohort 3; the five subjects did not have blood drawn because of delivery or were lost to follow-up. The median number of injections per subject was 19 (range 1-22), and all subjects received $\geq 80 \%$ of injections within a 7 -day interval.

\section{PK Results}

- Table 3 summarizes PK results, including AUC ${ }_{1-7}, C_{\max }$, $T_{\max }$, and mean trough levels. 17-OHPC and 17-OHPC-OH levels were adequate for analysis, while the levels of 17OHPC-diOH were below detectable levels to allow for detailed analysis.

Individual plots of 17-OHPC levels by gestational age and subject are shown in - Fig. 1. 17-OHPC PK, as measured by $C_{\max }$ and $\mathrm{AUC}_{1-7}$, were moderately variable in each cohort with \% coefficient of variation (\% $\mathrm{CV}$ ) values ranging from 30 to $40 \%$. After the first dose, the mean $\pm \mathrm{SD} C_{\max }$ level of $5.0 \pm 1.5 \mathrm{ng} / \mathrm{mL}$ was achieved by $119.8 \pm 50.1$ hours. The exposure to 17-OHPC, as assessed by AUC $_{1-7}$ after the first injection, was $571.4 \pm 195.2 \mathrm{ng} \times \mathrm{h} / \mathrm{mL}$. By 24 to 28 weeks and 32 to 36 weeks, mean $\pm \mathrm{SD} \mathrm{AUC}_{1-7}$ was $1,269.6 \pm 285.0$ $\mathrm{ng} \times \mathrm{h} / \mathrm{mL}$ and $1,268.0 \pm 511.6 \mathrm{ng} \times \mathrm{h} / \mathrm{mL}$, and mean $\pm \mathrm{SD}$ $C_{\max }$ values were $12.5 \pm 3.9 \mathrm{ng} / \mathrm{mL}$ and $12.3 \pm 4.9 \mathrm{ng} / \mathrm{mL}$, respectively. Mean $\pm \mathrm{SD} T_{\max }$ values were $28.6 \pm 9.0$ hours at weeks 24 to 28 and $43.7 \pm 20.2$ hours at weeks 32 to 36 . There was slow accumulation of the drug after the first administration, but by week 24 , an approximate steady state was reached.

17-OHPC-OH PK following the first dose and at 24 to 28 weeks varied, as exhibited by \%CV estimates of 37 to $46 \%$. 17-OHPC-OH PK was more variable at 32 to 36 weeks, with \%CV estimates of 54 to $56 \%$. After dose 1, the maximum 17-OHPC$\mathrm{OH}$ level was $1.9 \pm 0.7 \mathrm{ng} / \mathrm{mL}$, achieved by $\sim 113.6$ hours (median). Exposure to $17-\mathrm{OHPC}-\mathrm{OH}$, as assessed by $\mathrm{AUC}_{1-7}$, was $208.5 \pm 92.4 \mathrm{ng} \times \mathrm{h} / \mathrm{mL}$. Mean $\pm \mathrm{SD} C_{\max }$ estimates at 24 to 28 weeks and 32 to 36 weeks were $1.5 \pm 0.7 \mathrm{ng} / \mathrm{mL}$ and $1.8 \pm 1.0 \mathrm{ng} / \mathrm{mL}$, respectively. Mean $\pm \mathrm{SD} \mathrm{AUC}_{1-7}$ estimates were $157 \pm 64.6 \mathrm{ng} \times \mathrm{h} / \mathrm{mL}$ and $211 \pm 113.1 \mathrm{ng} \times \mathrm{h} / \mathrm{mL}$, respectively, at the same time points. Exposure to the 17OHPC-OH was approximately 6 to 10 times lower than that of 17-OHPC. 17-OHPC $C_{\max }$ and AUC increased following repeat injections. Summaries of 17-OHPC and 17-OHPC-OH levels are presented in -Figs. 2 and $\mathbf{3}$, respectively.

17-OHPC-diOH levels were $\sim 40$ times lower than 17-OHPC and four to five times lower than 17-OHPC-OH. 17-OHPC and 17-OHPC-OH trough levels were consistent at all measured time points and were, in general, also consistent with those for subjects sampled for 7 days in the same intervals.

The terminal half-lives of 17-OHPC and 17-OHPC-OH were determined. Although 10 subjects had blood draws after week 36 , serum levels did not decline in a log-linear

Table 3 PK results

\begin{tabular}{|c|c|c|c|c|}
\hline Time period & Dose 1 & Weeks 24-28 & Weeks 32-36 & Elimination \\
\hline Number of subjects for PK assessment & 6 & 8 & $11^{\mathrm{a}}$ & 10 \\
\hline Number of trough levels taken & 19 & 19 & 12 & \\
\hline \multicolumn{5}{|l|}{ 17-OHPC (mean \pm SD) } \\
\hline $\mathrm{AUC}(\mathrm{ng} \times \mathrm{h} / \mathrm{mL})^{\mathrm{b}}$ & $571.4 \pm 195.2$ & $1,269.6 \pm 285.0$ & $1,268.0 \pm 511.6$ & \\
\hline$C_{\max }(\mathrm{ng} / \mathrm{mL})$ & $5.0 \pm 1.5$ & $12.5 \pm 3.9$ & $12.3 \pm 4.9$ & \\
\hline$T_{\max }(\mathrm{h})$ & $119.8 \pm 50.1$ & $28.6 \pm 9.0$ & $43.7 \pm 20.2$ & \\
\hline Half-life (days) & & & & $16.3 \pm 3.6$ \\
\hline Clearance $\left(\lambda_{z}\right)(/ \mathrm{h})$ & & & & $0.002 \pm 0.0004$ \\
\hline$C_{\text {trough }}(\mathrm{ng} / \mathrm{mL})$ & $7.5 \pm 7.1$ & $10.0 \pm 4.8$ & $8.9 \pm 2.9$ & \\
\hline \multicolumn{5}{|l|}{ 17-OHPC-OH (mean \pm SD) } \\
\hline $\mathrm{AUC}(\mathrm{ng} \times \mathrm{h} / \mathrm{mL})^{\mathrm{b}}$ & $208.5 \pm 92.4$ & $157.1 \pm 64.6$ & $211.2 \pm 113.1$ & $1,205.2 \pm 995.2$ \\
\hline$C_{\max }(\mathrm{ng} / \mathrm{mL})$ & $1.9 \pm 0.7$ & $1.5 \pm 0.7$ & $1.8 \pm 1.0$ & $3.2 \pm 3.0$ \\
\hline$T_{\max }(\mathrm{h})$ & $107.7 \pm 44.9$ & $66.4 \pm 53.3$ & $91.5 \pm 43.8$ & $299.3 \pm 213.4$ \\
\hline Half-life (days) & & & & $19.7 \pm 6.2$ \\
\hline$C_{\text {trough }}(\mathrm{ng} / \mathrm{mL})$ & $0.6 \pm 0.3$ & $1.0 \pm 0.7$ & $0.8 \pm 0.8$ & \\
\hline \multicolumn{5}{|l|}{ 17-OHPC-diOH (mean \pm SD) } \\
\hline$C_{\max }(\mathrm{ng} / \mathrm{mL})$ & $<0.1$ & $0.28 \pm 0.12$ & $0.48 \pm 0.36$ & \\
\hline$T_{\max }(\mathrm{h})$ & $\mathrm{n} / \mathrm{a}$ & $81.0 \pm 51.2$ & $104.7 \pm 55.0$ & \\
\hline$C_{\text {trough }}(\mathrm{ng} / \mathrm{mL})$ & $<0.1$ & $0.28 \pm 0.14$ & $0.42 \pm 0.22$ & \\
\hline
\end{tabular}

Abbreviations: AUC, area under the time concentration curve; $C_{\max }$, maximum concentration; $C_{\text {trough }}$, trough concentration; $17-\mathrm{OHPC}$, hydroxyprogesterone caproate; 17-OHPC-diOH, di-hydroxylated hydroxyprogesterone caproate; 17-OHPC-OH, mono-hydroxylated hydroxyprogesterone caproate; $\mathrm{n} / \mathrm{a}$, not applicable; PK, pharmacokinetic; SD, standard deviation; $T_{\max }$, time to maximum concentration.

${ }^{a}$ Five of 16 patients did not have PK blood drawn due to delivery or lost to follow-up.

${ }^{\mathrm{b}} \mathrm{AUC}_{1-7}$ for treatment intervals and $\mathrm{AUC}_{0-28}$ for elimination phase. 
(A) Postdose 1

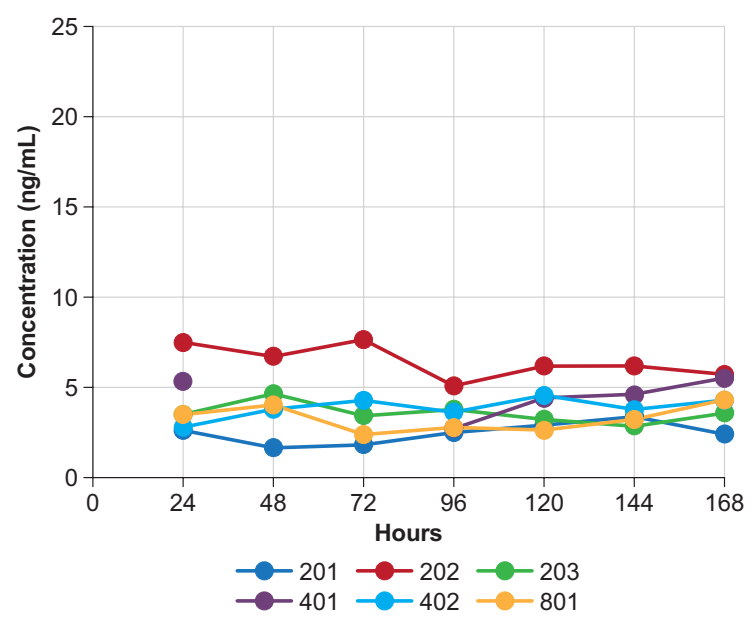

(C) Weeks 32-36

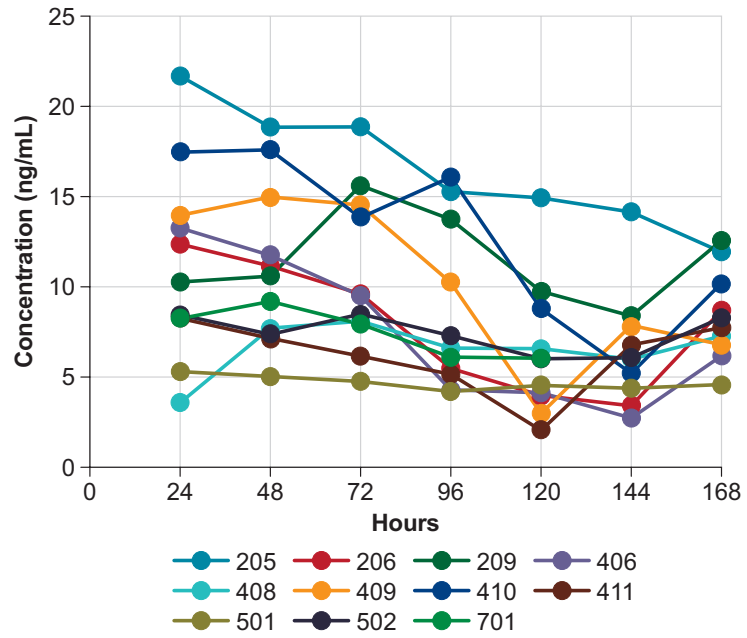

(B) Weeks 24-28

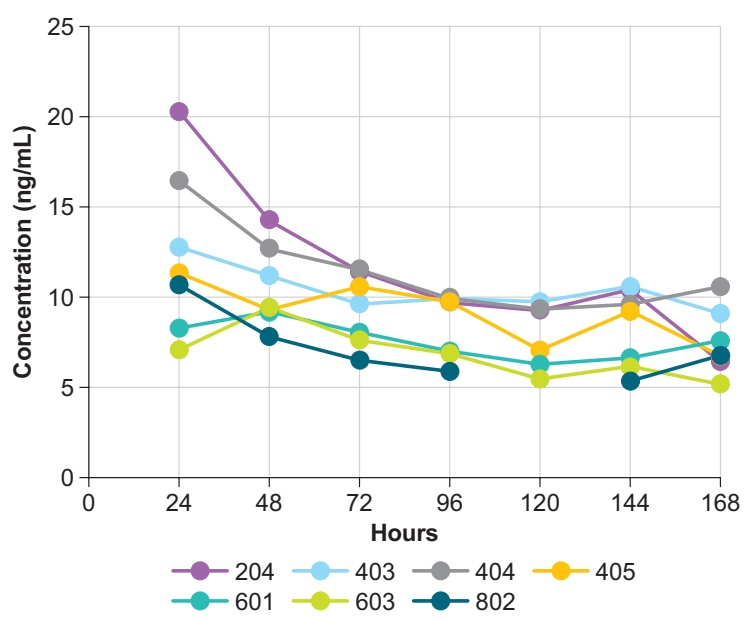

(D) Elimination Phase

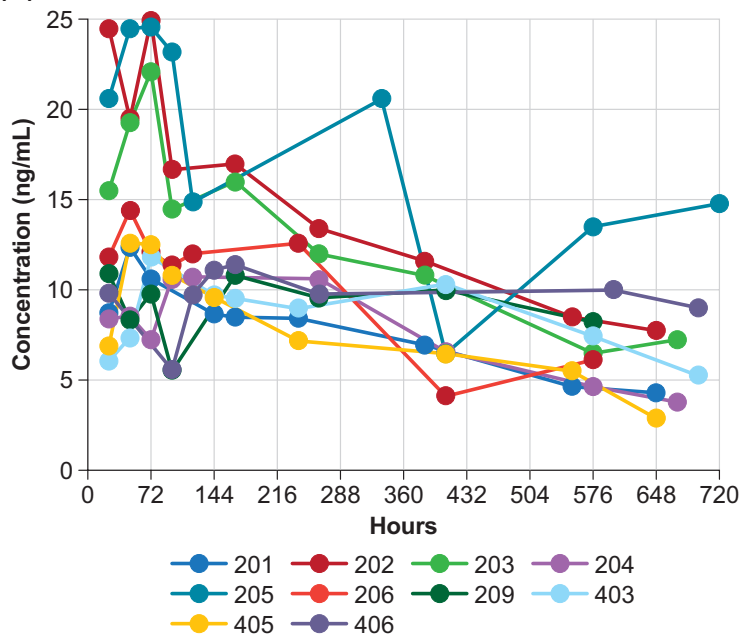

Fig. 1 17-OHPC levels (ng/mL) by subject and time in gestation: (A) Postdose 1; (B) Weeks 24-28; (C) Weeks 32-36, and (D) Elimination phase. $C_{\max }$ and $\mathrm{AUC}_{1-7} \%$ coefficient of variation ranged from 30 to $40 \%$.

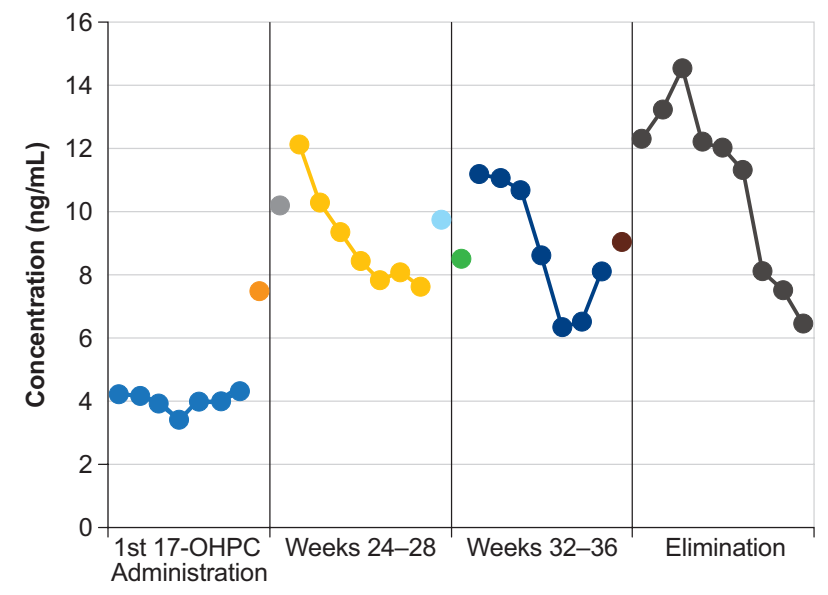

Mean 17-OHPC Values Throughout Pregnancy

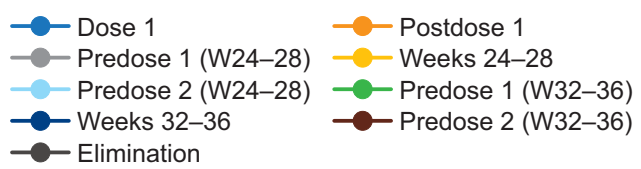

Fig. 2 Average daily 17-OHPC plasma concentration $(\mathrm{ng} / \mathrm{mL})$ throughout pregnancy by time in gestation and blood-draw schedule.

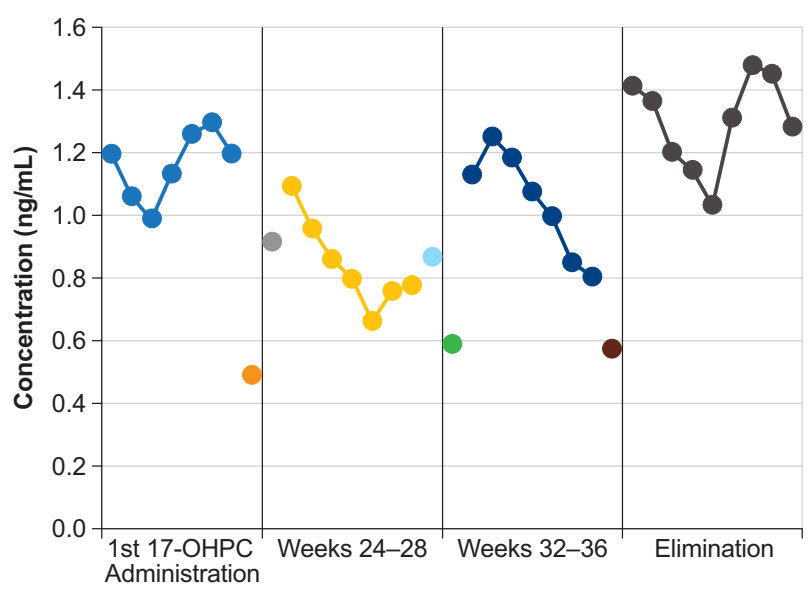

Mean 17-OHPC-OH Values Throughout Pregnancy

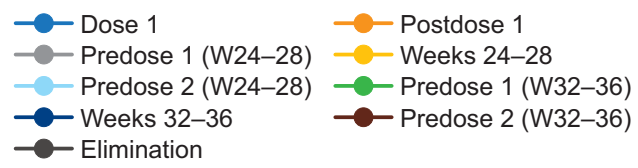

Fig. 3 Average daily 17-OHPC-OH plasma concentration $(\mathrm{ng} / \mathrm{mL})$ throughout pregnancy by time in gestation and blood-draw schedule. 
manner for six subjects; therefore, only 4 of the 10 subjects contributed data to the determination. The half-life was $16.3 \pm 3.6$ days and $19.7 \pm 6.2$ days for $17-$ OHPC and 17 $\mathrm{OHPC}-\mathrm{OH}$, respectively. At the end of the sampling interval, measurable levels were still evident for 17-OHPC (2.9$14.8 \mathrm{ng} / \mathrm{mL})$ and $17-\mathrm{OHPC}-\mathrm{OH}(1.4-2.0 \mathrm{ng} / \mathrm{mL})$. There was no difference in mean 17-OHPC trough levels measured between weeks 24 and 28 for women with a pre-pregnancy BMI $<30 \mathrm{~kg} / \mathrm{m}^{2}$ versus women with a BMI $\geq 30 \mathrm{~kg} / \mathrm{m}^{2}$ $(10.3 \pm 4.9$ versus $8.4 \pm 2.9$, respectively, $p=0.22)$. Four (29\%) of 14 subjects with a trough level less than the median at 24 to 28 weeks delivered preterm, compared with two (14\%) of 14 with a value above the median.

\section{Maternal Adverse Events, Pregnancy Complications, and Infant Outcomes}

Twenty-four (80.0\%) of 30 subjects experienced adverse events. The most common maternal adverse events were gastrointestinal. No subject discontinued 17-OHPC early except for preterm delivery. Twelve (40\%) of 30 women experienced pregnancy complications. Six (21\%) infants were born preterm (at $<37$ weeks), three spontaneous and three medically indicated. One subject had a miscarriage at 18 weeks 4 days, which was deemed unlikely to be drug related. Infant outcomes were available for 28 of 30 subjects. Twenty-seven infants were live-born. Mean gestational age was 36.3 weeks and mean birth weight was 2,965.5 g. Seven (25.9\%) infants were admitted to the NICU for a median of 10 days (range $1-99$ ).

\section{Discussion}

Our results define the PK parameters of 17-OHPC and its metabolites in 17-OHPC-treated pregnant women. At 24 weeks, 17-OHPC trough plasma levels were 8.9 to $10 \mathrm{ng} / \mathrm{mL}$, and corresponding $C_{\max }$ values were $\sim 12.5 \mathrm{ng} / \mathrm{mL}$, which is lower than reported by Caritis et al. ${ }^{4,5}$ The primary clinical trial of $17-O H P C$ for PTB prevention used $250-\mathrm{mg}$ weekly injections, with no PK data to inform that decision. ${ }^{6}$ The dose selected was the most commonly reported dose and was close to the drug solubility limit in $1 \mathrm{~mL}$ of the oil-based formulation. Previous studies used doses ranging from $250^{7,8}$ to $1,000 \mathrm{mg} /$ week. $^{9}$

Dose response may be an important factor for 17-OHPC efficacy for PTB prevention. In a secondary analysis of the Meis et al trial, ${ }^{6}$ Heyborne et al $^{10}$ concluded that $17-O H P C$ was effective in preventing repeat PTB only in women with a prepregnancy BMI $<30 \mathrm{~kg} / \mathrm{m}^{2}$. However, Meis et al ${ }^{11}$ previously reported that a high pregravid BMI in the placebo group was associated with a negative (protective) association with preterm delivery, while BMI did not affect the rate of preterm delivery in the 17-OHPC group. We did not find differences in PTB or 17-OHPC trough levels between obese and non-obese women. In a secondary analysis of 17-OHPC and omega-3 to prevent PTB, ${ }^{12}$ Caritis et al ${ }^{13}$ found that subjects with $17-\mathrm{OHPC}$ plasma levels in the lowest quartile had a higher risk of PTB and delivery at earlier gestational ages than women in the upper quartiles had. Our data did not demonstrate differences in PTB by 17-OHPC level quartile. Our sample size was not powered to detect differences in PTB by maternal BMI or 17-OHPC levels. Additional studies may be needed in certain populations, such as women with a higher BMI.

At the time of the FDA approval of 17-OHPC for PTB prevention, there was little understanding of 17-OHPC PKs. A study of women with endometrial cancer on long-term 17OHPC ( $1,000 \mathrm{mg}$ daily for 5 days followed by $1,000 \mathrm{mg}$ every 2 weeks) found that 17-OHPC levels peaked 2 weeks following drug initiation, and that women treated with weekly injections had higher serum levels than those treated every 2 weeks had. ${ }^{14}$ Subsequently, two studies reported the PK of 17-OHPC. In 61 women with singleton pregnancies receiving 17-OHPC, Caritis et $\mathrm{al}^{4}$ reported that the half-life of 17-OHPC was 16.2 days, and levels were higher at 31 to 35 weeks than 20 to 25 weeks. In women pregnant with twins or triplets, the half-life of 17-OHPC was 10 days. $^{5}$

The half-life of 16.3 days we report is an apparent half-life, the net result of drug being eliminated from the plasma while simultaneously being replaced by drug absorbing from the oil depot in the muscle. The half-life of 17-OHPC itself in the blood may be much shorter. In a PK study of a novel oral formulation of 17-OHPC, dosing twice a day was needed to maintain blood levels. ${ }^{15}$ In a study of a cremophor:ethanolbased formulation in rats, the half-life was 10.6 hours when given intravenously but was not reached after 120 hours when given intramuscularly. ${ }^{16}$

We provide information that has not been previously published, including PK after the first dose and quantification of 17-OHPC-OH and 17-OHPC-diOH. A limitation of our analysis is that we did not collect trough samples during intensive PK studies at 24 to 28 and 32 to 36 weeks, thus we can only speculate on trough levels as pregnancy advances. Further research is needed to determine whether these metabolites are active. Our findings confirm previous observations that 17-OHPC has a long terminal half-life and accumulates with multiple dosing until a steady state is reached. However, our reported levels are lower than those reported by Caritis et al. ${ }^{4}$ Given the similar methodology, the reason for the difference is unclear, although there were differences in sampling times relative to dosing. Our results were produced using a validated assay where validation and sample analysis were commensurate with international standards of Good Laboratory Practice.

Concentrations of 17-OHPC and 17-OHPC-OH reach steady state by weeks 24 to 28 , but there is considerable variability among subjects. The reasons for this variability remain unclear. Possibly there are absorption or metabolism differences, and these differences could impact drug levels. Other factors that can lead to variability of plasma levels include age, hormonal status, conditions at the absorption site, circulation to the absorption site, and area of the absorbing surface (determined largely by the route of administration). ${ }^{5,17,18}$ Our objective was to measure the PKs of 17-OHPC and its metabolites throughout pregnancy. Future studies are needed to determine the reasons for inter-woman variability and the potential impact of efficacy for recurrent PTB prevention. 


\section{Conflict of Interest}

Robert Birch was an employee of AMAG Pharmaceuticals. The remaining authors declare no conflict of interest.

\section{Acknowledgments}

AMAG Pharmaceuticals funded the study. The sponsor designed the study and provided administrative support for the manuscript. The study was registered on clinicaltrials.gov (https://www.clinicaltrials.gov/) NCT01899846. Poster was presented at 62nd Annual Scientific Meeting of the Society for Reproductive Investigation, San Francisco, California, March 25-28, 2015.

\section{References}

1 Blencowe H, Cousens S, Oestergaard MZ, et al. National, regional, and worldwide estimates of preterm birth rates in the year 2010 with time trends since 1990 for selected countries: a systematic analysis and implications. Lancet 2012;379(9832):2162-2172

2 Martin JA, Hamilton BE, Sutton PD, et al. Births: final data for 2006. Natl Vital Stat Rep 2009;57(07):1-104

3 Martin JA, Hamilton BE, Osterman MJ, Curtin SC, Matthews TJ. Births: final data for 2013. Natl Vital Stat Rep 2015;64(01):1-65

4 Caritis SN, Sharma S, Venkataramanan R, et al; Eunice Kennedy Shriver National Institute of Child Health and Human Development Obstetrical-Fetal Pharmacology Research Units Network. Pharmacology and placental transport of 17-hydroxyprogesterone caproate in singleton gestation. Am J Obstet Gynecol 2012; 207(05):398.e1-398.e8

5 Caritis SN, Sharma S, Venkataramanan R, et al; Eunice Kennedy Shriver National Institute of Child Health and Human Development Maternal-Fetal Medicine Units Network. Pharmacokinetics of 17-hydroxyprogesterone caproate in multifetal gestation. Am J Obstet Gynecol 2011;205(01):40.e1-40.e8

6 Meis PJ, Klebanoff M, Thom E, et al; National Institute of Child Health and Human Development Maternal-Fetal Medicine Units Network. Prevention of recurrent preterm delivery by 17 alphahydroxyprogesterone caproate. N Engl J Med 2003;348(24): 2379-2385

7 Johnson JW, Austin KL, Jones GS, Davis GH, King TM. Efficacy of 17alpha-hydroxyprogesterone caproate in the prevention of premature labor. N Engl J Med 1975;293(14):675-680
8 Johnson JW, Lee PA, Zachary AS, Calhoun S, Migeon CJ. High-risk prematurity-progestin treatment and steroid studies. Obstet Gynecol 1979;54(04):412-418

9 Hauth JC, Gilstrap LC III, Brekken AL, Hauth JM. The effect of $17 \alpha$-hydroxyprogesterone caproate on pregnancy outcome in an active-duty military population. Am J Obstet Gynecol 1983;146 (02):187-190

10 Heyborne KD, Allshouse AA, Carey JC. Does 17-alpha hydroxyprogesterone caproate prevent recurrent preterm birth in obese women? Am J Obstet Gynecol 2015;213(06):844.e1-844.e6

11 Meis PJ, Klebanoff M, Dombrowski MP, et al. Does progesterone treatment influence risk factors for recurrent preterm delivery? Obstet Gynecol 2005;106(03):557-661

12 Harper M, Thom E, Klebanoff MA, et al; Eunice Kennedy Shriver National Institute of Child Health and Human Development Maternal-Fetal Medicine Units Network. Omega-3 fatty acid supplementation to prevent recurrent preterm birth: a randomized controlled trial. Obstet Gynecol 2010;115(2 Pt 1):234-242

13 Caritis SN, Venkataramanan R, Thom E, et al; Eunice Kennedy Shriver National Institute of Child Health and Human Development Maternal-Fetal Medicine Units Network and Obstetric-Fetal Pharmacology Research Units Network. Relationship between 17-alpha hydroxyprogesterone caproate concentration and spontaneous preterm birth. Am J Obstet Gynecol 2014;210(02):128.e1-128.e6

14 Onsrud M, Paus E, Haug E, Kjørstad K. Intramuscular administration of hydroxyprogesterone caproate in patients with endometrial carcinoma. Pharmacokinetics and effects on adrenal function. Acta Obstet Gynecol Scand 1985;64(06):519-523

15 DelConte A, Chidambaram N, Nachaegari S, Patel M, Venkateshwaran S. Pharmacokinetics and tolerability of oral 17-hydroxyprogesterone caproate (HPC) relative to intramuscular (IM) HPC. Am J Obstet Gynecol 2015;212(01):S374

16 Shaik IH, Bastian JR, Zhao Y, Caritis SN, Venkataramanan R. Route of administration and formulation dependent pharmacokinetics of 17-hydroxyprogesterone caproate in rats. Xenobiotica 2016;46 (02):169-174

17 Yan R, Nanovskaya TN, Zharikova OL, Mattison DR, Hankins GD Ahmed MS. Metabolism of 17alpha-hydroxyprogesterone caproate by hepatic and placental microsomes of human and baboons. Biochem Pharmacol 2008;75(09):1848-1857

18 Paulson RJ, Collins MG, Yankov VI. Progesterone pharmacokinetics and pharmacodynamics with 3 dosages and 2 regimens of an effervescent micronized progesterone vaginal insert. J Clin Endocrinol Metab 2014;99(11):4241-4249 